\title{
La galería porticada románica en tierras de Castilla
}

\author{
José Arturo SAlgado Pantoja \\ Departamento de Historia del Arte \\ Universidad de Castilla-La Mancha \\ JoseArturo.Salgado@uclm.es
}

\section{RESUMEN}

Nuestra tesis doctoral está centrada en el análisis de las galerías porticadas románicas, estructuras arquitectónicas de gran relevancia en el reino de Castilla entre los siglos XI y XIII. En este artículo presentamos algunas de las principales aportaciones y conclusiones de nuestra investigación.

Palabras clave: Pórtico; Románico; Castilla; Estructura; Arquitectura.

\section{Romanesque porticoes in Castile}

\begin{abstract}
The author's PhD dissertation focuses on the analysis of the Romanesque portico - a much extended architectonic structure in the Kingdom of Castile between the $11^{\text {th }}$ and $13^{\text {th }}$ centuries. Some of the author's main findings and contributions are presented on this paper.
\end{abstract}

Key words: Portico; Romanesque; Castile; Structure; Architecture. 
La gran dispersión geográfica que logró el arte románico, provocó el surgimiento de una extraordinaria pluralidad de manifestaciones dentro de un mismo estilo artístico, con cronologías, características o peculiaridades a menudo relacionadas con el sustrato propio de cada ámbito territorial. Ese hecho tuvo su reflejo en el solar ibérico, tierra de encuentro entre culturas en la que el arte románico, fusionado con la tradición constructiva autóctona, se plagó de numerosas singularidades. De entre todas ellas, nuestra investigación se detiene en una muy particular: las galerías porticadas. Estas estructuras, características del románico castellano, aun admitiendo la existencia de otras muchas y muy heterogéneas que las anteceden, lograron un desarrollo sin parangón en los territorios cristianos peninsulares de los siglos XI al XIII. No obstante, y pese a la gran proliferación de esta tipología constructiva, su estudio ha permanecido casi inexistente hasta fechas relativamente recientes.

Con el presente artículo se realiza un acercamiento al tema central de nuestra Tesis doctoral, que versa sobre El pórtico románico en tierras de Castilla. ${ }^{1}$ En concreto, se abordan los principales puntos del estudio: el estado de la cuestión, algunos planteamientos básicos sobre las estructuras porticadas, los procedimientos para la catalogación de ejemplares y un repaso por las más relevantes aportaciones de la investigación dentro del marco científico de la Historia del Arte.

\section{UN BREVE ESTADO DE LA CUESTIÓN}

Aun a pesar de la valiosa labor de los autores que han prestado atención al estudio de los pórticos románicos, el reducido número de trabajos específicos sobre los mismos conduce, con excesiva frecuencia, a las ya manidas páginas de las grandes publicaciones sobre la Historia y el Arte del Medioevo. Este hecho, sin embargo, no hace sino acrecentar nuestra motivación e interés por retomar esa atractiva aunque desarticulada herencia, urgida de nuevos datos, planteamientos y conclusiones.

Con un fin esencialmente metodológico, se han agrupado los trabajos de investigación sobre el tema que nos ocupa en dos grandes bloques. El primero engloba a un buen número de autores clásicos, afanados en buscar clasificaciones tipológicas $\mathrm{y}$, principalmente, en plantear teorías sobre el origen de los espacios porticados. Por su parte, el segundo grupo está integrado por investigaciones efectuadas durante las cuatro últimas décadas y, por consiguiente, sustentadas en nuevas aportaciones arqueológicas y documentales.

En un artículo publicado en 1975, Bango Torviso ofrece el más completo estado de la cuestión realizado hasta ese momento. Ya desde el inicio de su trabajo, el autor lamenta la carencia de estudios centrados en la galería porticada peninsular, a la vez que, quizá de manera no premeditada, va estableciendo algunas de las bases para una nueva forma de analizar y valorar estas estructuras de nuestro románico ${ }^{2}$.

\footnotetext{
1 Dicha investigación, dirigida por el Dr. Miguel Cortés Arrese, catedrático de Historia del Arte de la Universidad de Castilla-La Mancha, fue defendida el 12 de julio de 2012, y será publicada próximamente.

2 BANGO TORVISO, Isidro Gonzalo, "Atrio y pórtico en el románico español: concepto y finalidad cívico-litúrgica", en Boletín del Seminario de Estudios de Arte y Arqueología, no 40-41, 1975, p. 175, nota 1.
} 
Una de las pocas salvedades, como adelanta Bango Torviso, se encuentra en una obra de Taracena Aguirre, en la que se efectúa un interesante repaso de la evolución de la galería porticada románica. Para ello, establece como punto de partida los ejemplares de San Esteban de Gormaz, a partir de los cuales se iniciaría una tipología constructiva que, ganando progresivamente en esbeltez y dimensiones, llega a su cenit en galerías como las de Tiermes y Caracena ${ }^{3}$. Dicho planteamiento, si bien resulta novedoso, tiene como lastre el desconocimiento de un buen número de iglesias románicas porticadas por aquella época, hecho que conduce a unas conclusiones extremadamente sesgadas (fig.1).

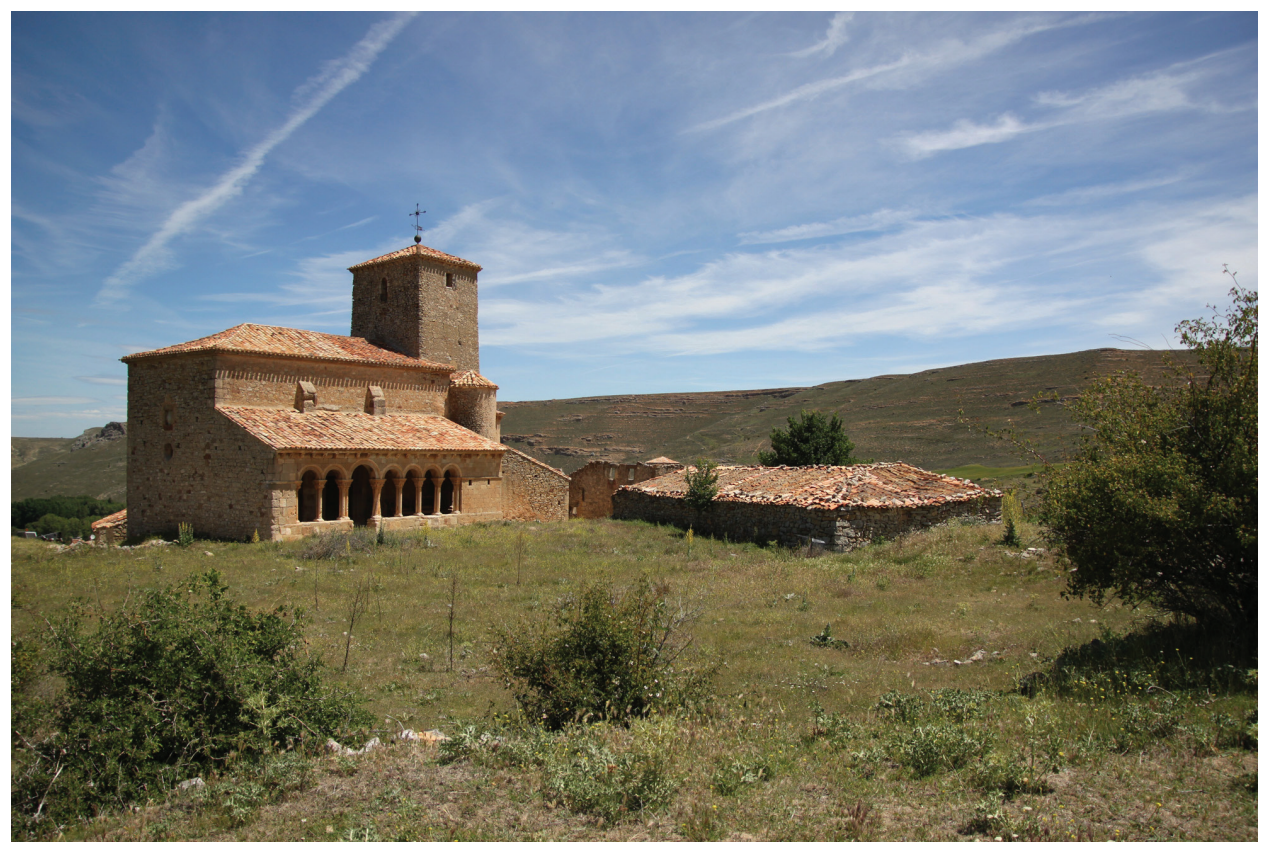

Fig. 1. Iglesia de San Pedro, Caracena (Soria), último cuarto S. XII. [Foto autor].

En cualquier caso, la principal meta de estos investigadores pioneros será la búsqueda de un origen para el pórtico románico. El hecho de que estas estructuras no proliferasen en Francia, Alemania, Italia u otros países fronteros, provocó un aluvión de teorías, la mayoría inserta, con sus evidentes matices, dentro de dos diferentes tendencias. La primera, sostenida por autores como el Marqués de Lozoya o GómezMoreno, incluyen estas estructuras dentro de un fenómeno de filiación peninsular. No obstante, mientras que aquél opina que son fruto principalmente de las necesi-

3 TARACENA AGUIRRE, Blas, "Notas de arquitectura románica. Las galerías porticadas", en Boletín de la Biblioteca Menéndez Pelayo, nº 9, 1933, pp. 3-18. 
dades climáticas castellanas ${ }^{4}$, Gómez-Moreno cree percibir cierta continuidad entre los ejemplares prerrománicos peninsulares que estudia y los del románico soriano, padres, como luego volverá a afirmar Taracena Aguirre, de los segovianos ${ }^{5}$.

De forma paralela, otro grupo de estudiosos aboga por un origen más exótico para la galería porticada, generalmente vinculado con Oriente Próximo. Aunque muchos son los que sostienen dicha hipótesis incluso bien entrado el siglo XX, pocos o casi ninguno de ellos logran establecer una argumentación suficientemente sólida para apoyarla con total firmeza. Una de las primeras menciones la realiza Goddard King ${ }^{6}$, para quien los pórticos hispanos imitan modelos sirios traídos por los Caballeros del Santo Sepulcro. También Gaya Nuño comparte la idea del origen siriaco, pero considera que el trasvase artístico fue fruto de la convivencia afectuosa entre cristianos y musulmanes ${ }^{7}$. Años antes, Lampérez y Romea ya había adelantado ese planteamiento, si bien incidiendo en el dato de que el pórtico románico había proliferado especialmente en regiones con una gran abundancia de conversos ${ }^{8}$.

Todos los autores citados ponen de manifiesto un relativo interés por la búsqueda de unas raíces comunes para los pórticos del románico castellano. Sin embargo, apenas existen menciones a la riqueza funcional de los mismos en estas publicaciones de los primeros tres cuartos del siglo XX. A la citada apreciación de Lampérez y Romea sólo se puede sumar la realizada por Serrano Fatigati, que ya aventura la existencia de un sincretismo de funciones cívico-litúrgicas que vincula estrechamente al de los claustros monásticos ${ }^{9}$.

En cualquier caso, el punto de inflexión en el estudio de las galerías porticadas de los siglos XI al XIII es, sin duda alguna, el ya referido trabajo de Bango Torviso ${ }^{10}$. En este artículo, y tras unas pequeñas pero convenientes aclaraciones terminológicas, se aborda el primer estudio sistemático y documentado de los usos de la galería porticada, diferenciando entre cuatro distintas funciones: centro de reuniones laicas, litúrgica, de esparcimiento y ad tumulandum. Desde la perspectiva de esta última, la

4 CONTRERAS Y LÓPEZ DE AYALA, Juan de, Marqués de Lozoya, El románico segoviano, Segovia, Caja de Ahorros y Monte de Piedad de Segovia, 1967, p. 18. Otro autor que entiende el pórtico como un elemento ligado al clima es George Edmund Street: "The object of these external cloisters has been, I relieve, matter of considerable discussion, yet I confess that they always seemed to me to be adopted mainly, if not solely, on account of the excessive heat in Spain in summer". STREET, George Edmund, Some account of Gothic architecture in Spain, Londres, John Murray, 1865, p. 190.

5 GÓMEZ-MORENO MARTÍNEZ, Manuel, Iglesias mozárabes. Arte español de los siglos IX al XI, Madrid, Centro de Estudios Históricos, 1919, pp. 154-155.

6 GODDARD KING, Georgiana, "Algunos rasgos de influjo oriental en la arquitectura española de la Edad Media”, en Arquitectura, no 5, 1923, pp. 85-193.

7 GAYA NUÑO, Juan Antonio, El románico en la provincia de Soria, facsímil de la edición de 1946, Madrid, Instituto de Historia. CSIC. Centro de Estudios Sorianos, 2003, pp. 15-16.

8 LAMPÉREZ Y ROMEA, Vicente, Historia de la Arquitectura Cristiana Española en la Edad Media según el estudio de los elementos y los monumentos, I, Madrid, Espasa-Calpe, 1930, p. 206.

9 SERRANO FATIGATI, Enrique, "Portadas del periodo románico y del de transición al ojival", en Boletín de la Sociedad Española de Excursiones, t. XIV, nº 156, 1906, p. 8.

10 BANGO TORVISO, Isidro Gonzalo (1975) op. cit., pp. 175-188. 
cementerial, el mismo autor publica más tarde otro trabajo, en el que dedica un capítulo concreto a los espacios porticados ${ }^{11}$.

No obstante, hasta épocas relativamente cercanas escasean las referencias a nuestro objeto de estudio. Éstas tan sólo aparecen en obras muy generales, siendo una de las pocas excepciones un trabajo realizado por Ruiz Montejo ${ }^{12}$, en el que se retoma el debate acerca del origen de las galerías porticadas castellanas, iniciado décadas atrás tras el descubrimiento de una discutida fecha grabada en un canecillo del pórtico de San Miguel, en San Esteban de Gormaz (Soria) ${ }^{13}$. En los últimos años, también son relevantes las investigaciones efectuadas por Martínez Tejera, centradas principalmente en el análisis de los usos y el significado de los pórticos y otros "espacios intermedios", situados a medio camino entre el recinto sagrado y el ámbito externo de los templos de culto ${ }^{14}$. En otro artículo, aparecido en el catálogo de Las Edades del Hombre de 2009, se efectúa una revisión de la dimensión funcional de las galerías, añadiendo interesantes datos acerca de las características estructurales de las mismas o de los recientes descubrimientos de algunos ejemplares en la provincia de Soria ${ }^{15}$.

Con la llegada del nuevo milenio, se produce la eclosión de un ambicioso proyecto: la creación de un inventario de obras románicas y mudéjares en España. A partir de 2002, momento en que ven la luz los primeros tomos de la Enciclopedia del Románico, han ido apareciendo paulatinamente nuevas entregas. En la actualidad, ya han sido publicados los catálogos de Castilla y León, Cantabria, Asturias, La Rioja, Navarra, Madrid, Castilla-La Mancha y Zaragoza, amén de los recientes volúmenes del País Vasco ${ }^{16}$. Las monografías que componen esta compilación de obras, editada por la Fundación Santa María la Real, resulta imprescindible para emprender un trabajo como el nuestro, pues ofrece una completa recopilación de información y bibliografía referente a todas y cada una de las iglesias románicas porticadas.

11 BANGO TORVISO, Isidro Gonzalo, "El espacio para enterramientos privilegiados en la arquitectura medieval española”, en Anuario del Departamento de Historia y Teoría del Arte, no 4, 1992, pp. 93-132.

12 RUIZ MONTEJO, Inés, "Focos primitivos del románico castellano. Cronología y planteamientos de taller. Una aproximación a la problemática de los pórticos”, en Goya, n 158, 1980, pp. 86-93.

13 El descubridor de la misma, Ortego y Frías, leyó 1081, admitiéndola como data para la construcción de la estructura. Así lo señaló dos décadas más tarde en ORTEGO Y FRÍAS, Teógenes, "En torno al románico de San Esteban de Gormaz. Una fecha y dos artífices desconocidos”, en Celtiberia, n 13, 1957, pp. 79-103.

14 MARTÍNEZ TEJERA, Artemio Manuel, "De nuevo sobre áreas ceremoniales y espacios arquitectónicos intermedios en los edificios hispanos (ss. IV-X): atrio y pórtico", en Boletín de Arqueología Medieval, n 7 , 1993, pp. 163-215. MARTÍNEZ TEJERA, Artemio Manuel, "El pórtico románico: origen y funcionalidad de un espacio arquitectónico intermedio de la edilicia medieval hispana (atrium/porticus/vestibulum)", en Espacios y estructuras singulares del edificio románico, Aguilar de Campoo, 2008. LÓPEZ QUIROGA, Jorge y MARTÍNEZ TEJERA, Artemio Manuel, “De corporibus defunctorum: Lectura e interpretación históricoarqueológica del canon XVIII del Primer Concilio de Braga (a. 561) y su repercusión en la arquitectura hispana de la Antigüedad Tardía", en Morir en el Mediterráneo Medieval: Actas del III Congreso de Arqueología, Arte e Historia de la Antigüedad Tardía y Alta Edad Media peninsular (Madrid, 17-18 de diciembre de 2007), Madrid, 2009, pp. 153-182.

15 ESTERAS MARTÍNEZ, José Ángel, GONZALO CABRERIZO, César y LORENZO ARRIBAS, Josemi, "Claustros y galerías porticadas en el románico de Soria", en ATIENZA BALLANO, Juan Carlos (coord.), Paisaje interior, catálogo de la exposición de Las Edades del Hombre, Soria, 2009, pp. 125-162.

16 GARCÍA GUINEA, Miguel Ángel y PÉREZ GONZÁLEZ, José María (dirs.), Enciclopedia del Románico en el País Vasco, 3 vols., Aguilar de Campoo, Fundación Santa María la Real. Centro de Estudios del Románico, 2011. 
En las últimas tres décadas, buena parte de los estudios centrados en las estructuras intermedias, adosadas a los templos de culto, proceden del campo de la Arqueología. Pese a que en la práctica totalidad de los casos los ejemplos analizados se adscriben al periodo prerrománico, dicha información resulta enormemente valiosa para conocer algunos de los posibles precedentes de los pórticos de época románica. Ante la imposibilidad de citar todas las aportaciones, referimos al menos algunas de los concernientes a las obras más significativas para nuestro trabajo ${ }^{17}$.

De igual manera, existe una nutrida nómina de publicaciones que tratan sobre grupos de obras o ejemplos muy específicos. Muchos de ellos aparecen en libros de actas o en revistas de carácter local como Estudios Segovianos ${ }^{18}$, Wad-al-Hayara ${ }^{19}$, Celtiberia $^{20}$, etc. Por último, cabe indicar la importante labor de conservación y divulgación del arte románico llevada a cabo por planes de intervención como los encabezados por la citada Fundación Santa María la Real (Románico Norte y Ro-

17 OLMO ENCISO, Lauro, "Arquitectura religiosa y organización litúrgica en época visigoda. La basílica de Recópolis", en Archivo Español de Arqueología, no 157-158, 1988, pp. 157-178. BUENO ROCHA, José y CABALLERO ZOREDA, Luis, "De nuevo a propósito de la basílica de Recópolis", en Archivo Español de Arqueología, no 159-160, 1989, pp. 283-291. LARRÉN IZQUIERDO, Hortensia, "San Miguel de Escalada: trabajos arqueológicos 1983-1987", en Nvmantia. Arqueología en Castilla y León, n 3, 1990, pp. 217-240. CABALLERO ZOREDA, Luis, "Iglesia de El Gatillo de Arriba, Cáceres", en MATEOS CRUZ, P. y CABALLERO ZOREDA, L. (eds.), Repertorio de Arquitectura Cristiana en Extremadura: Época Tardoantigua y Altomedieval, Mérida, Instituto de Arqueología, 2003. CABALLERO ZOREDA, L., MATEOS CRUZ, P. y UTRERO AGUDO, M. A. (coords.), El siglo VII frente al siglo VII. Arquitectura (Visigodos y Omeyas, 4, Mérida, 2006), Madrid, 2009. ARCE SÁIZ, Fernando, "La iglesia altomedieval de San Vicente del Valle (Burgos): historiografía, estratigrafía e interpretación”, en Arqueología de la arquitectura, n 7, 2010, pp. 67-103.

18 CABELlO DODERO, Francisco Javier, "La arquitectura románica en Segovia", en Estudios Segovianos, $\mathrm{n}^{\circ} 10,1952$, pp. 5-37. CALLEJA GUIJARRO, Tomás, "La arqueología, la historia y la leyenda en torno a las Vegas de Pedraza", en Estudios Segovianos, no 49, 1965, pp. 5-61. SANTAMARÍA LÓPEZ, Juan Manuel, "Las iglesias románicas de la Comunidad de Villa y Tierra de Pedraza", en Estudios Segovianos, $\mathrm{n}^{\circ}$ 68-69, 1971, pp. 155-204. BARRIO ÁLVAREZ, Yolanda del y LÓPEZ AMBITE, Fernando, "Resultados de la excavación de la Santísima Trinidad de Segovia", en Estudios Segovianos, no 97, 1998, pp. 35-48. MERINO DE CÁCERES, José Miguel y REYNOLDS ÁLVAREZ, María, "La iglesia de San Lorenzo de Segovia", en Estudios Segovianos, no 103, 2003, pp. 245-279. MERINO DE CÁCERES, José Miguel y REYNOLDS ÁLVAREZ, María, "La iglesia de San Martín de Segovia. Análisis morfológico y evolutivo", en Estudios Segovianos, $\mathrm{n}^{\circ} 105,2005$, pp. 219-262.

19 LÓPEZ DE LOS MOZOS, José Ramón, "Mitología en la iglesia románica de Pinilla de Jadraque", en Wad-al-Hayara, $\mathrm{n}^{\circ}$ 2, 1975, pp. 39-49. ASENSIO RODRÍGUEZ, Ana María, "Arquitectura románica en el partido judicial de Cogolludo", en Wad-al-Hayara, no 3, 1976, pp. 49-58. ASENSIO RODRÍGUEZ, Ana María, "La arquitectura románica en el partido de Atienza", en Wad-al-Hayara, no 5, 1978, pp. 89-101. HERRERA CASADO, Antonio, "La iglesia parroquial de Jodra del Pinar", en Wad-al-Hayara, no 7, 1980, pp. 283-285. HERRERA CASADO, Antonio, "Galerías porticadas románicas en Guadalajara. Algunos hallazgos recientes", en Wad-al-Hayara, $\mathrm{n}^{\circ} 15,1988$, pp. 413-418.

20 MARÍAS FRANCO, Fernando, "Las galerías porticadas del siglo XVI. La muerte de una tipología", en Celtiberia, no 47, 1974, pp. 51-74. QUIÑONES COSTA, Ana María, "Estudio arquitectónico e iconográfico del pórtico de la iglesia de Omeñaca", en Celtiberia, nº 68, 1984, pp. 207-220. ORTEGO Y FRÍAS, Teógenes, "Alcozar, la iglesia de San Esteban. Ruina histórico-artística de la villa", en Celtiberia, no 70, 1985, pp. 331-338. PALOMERO ARAGÓN, Félix, "Aproximación a la escultura monumental románica de la ermita de Santa María de Tiermes”, en Celtiberia, nº 78, 1987, pp. 127-153. MORALES HERNÁNDEZ, Fernando y BOROBIO SOTO, María José, "Resultados de las excavaciones en San Pedro de Caracena (Soria). Julio 1986: (Una aportación de la Arqueología a la Historia del Arte)”, en Celtiberia, no 81-82, 1991, pp. 211-251. 
mánico de Guadalajara) y la Fundación Duques de Soria (Proyecto Cultural Soria Románica) (fig. 2).

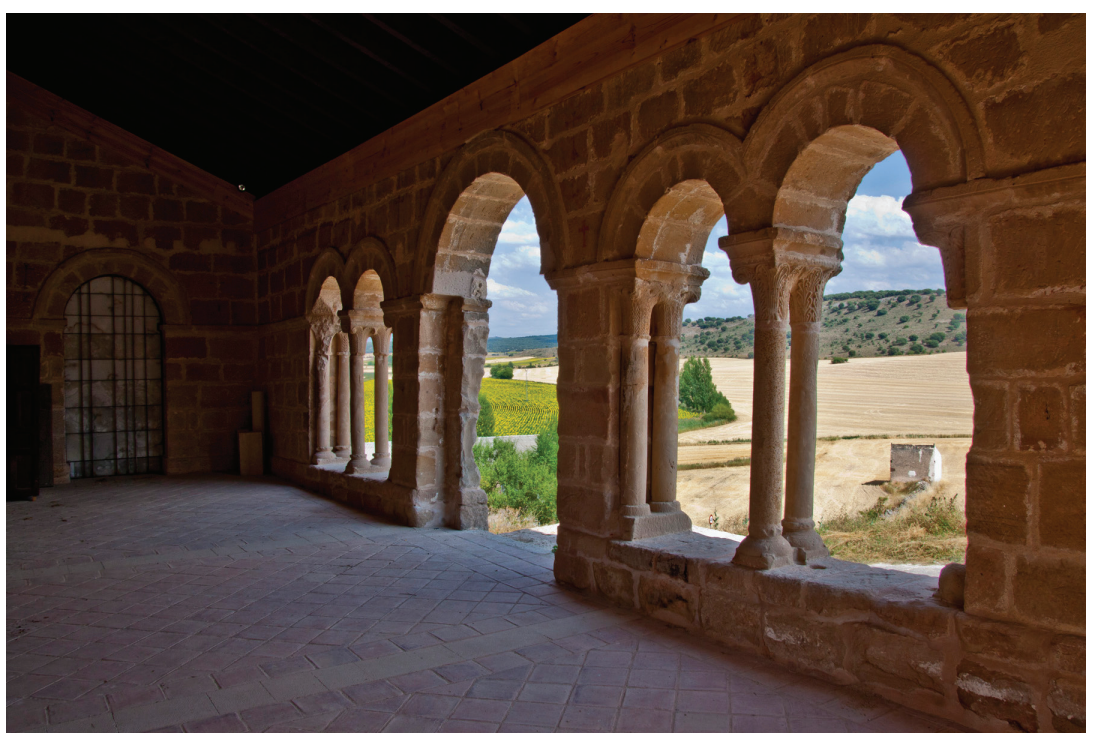

Fig. 2. Pórtico de la iglesia de San Juan Bautista, Jodra del Pinar (Guadalajara), principios S. XIII. Primera actuación del "Plan de Intervención Románico de Guadalajara". [Foto autor].

\section{LA GALERÍA PORTICADA COMO OBJETO DE ESTUDIO}

A la hora de abordar el estudio de los pórticos románicos castellanos, hemos tomado en consideración una serie de aspectos básicos para su análisis y clasificación. Los principales, que indicaremos de forma organizada en el presente artículo, son los referentes a la terminología, génesis y evolución de estas estructuras, así como a sus tres dimensiones fundamentales: la morfológica, la iconográfica y la simbólicofuncional.

En primer lugar, hemos considerado conveniente efectuar unas precisiones terminológicas para delimitar qué debemos entender por "pórtico" o "galería porticada" y qué no. En palabras de Bango Torviso, "hay tres conceptos arquitectónicos que se confunden: atrio, pórtico y portada" 21 . A éstos podríamos añadir otros como vestíbulo, alpendre, dextro, porche, portal, portegado, y así, un casi interminable etcétera. No obstante, si bien todos ellos sirven para designar elementos situados ante el umbral de acceso al templo, lo cierto es que la pluralidad de estructuras y espacios a los

21 BANGO TORVISO, Isidro Gonzalo, (1975), op. cit., p. 176. 
que hacen referencia suponen un verdadero obstáculo a la hora de abordar un trabajo de investigación.

En consecuencia, y por lo que a nuestro estudio respecta, cuando hablamos de pórtico o galería porticada nos referimos a una estructura arquitectónica, parcialmente abierta al exterior mediante vanos y cubierta. Se adosa al templo, generalmente en un impulso constructivo posterior al de éste, y queda estrechamente ligada a él, a medio camino entre su interior y su exterior. El atrio, sin embargo, es un espacio abierto, situado en el entorno jurisdiccional del templo, y a menudo delimitado por un muro que puede estar amojonado con cruces o estelas ${ }^{22}$. Cabe señalar que, aunque desde la perspectiva funcional el pórtico y el atrio pudieron compartir muchas de sus funciones, es muy probable que el primero, por su cercanía al edificio de culto y su carácter monumental, gozase de un carácter preferencial con respecto al segundo: cementerio privilegiado, estación central de las procesiones, etc.

Por otro lado, ya hemos hecho referencia a que la búsqueda del origen para un elemento arquitectónico tan extraordinario como la galería porticada fue una constante para los primeros estudiosos del tema. Aunque la cuestión hoy sigue abierta, la heterogeneidad formal y funcional de los ejemplares internacionales anteriores al románico parece estar más ligada a las necesidades de la comunidad humana que hizo uso de ellos que a modelos prefijados o recurrentes. Por ello, y ante lo infructuoso de la búsqueda de unas posibles raíces en ámbitos espaciotemporales alejados, hemos hecho un especial hincapié en el análisis de los principales casos del prerrománico hispano, pues, aun admitiendo sus evidentes diferencias con los pórticos que se desarrollan desde finales del siglo XI, poseen al menos una gran cercanía geográfica.

A pesar de la existencia de varias estructuras analizadas en nuestro trabajo, de cronología tardoantigua o altomedieval (Marialba de la Ribera, Recópolis, San Salvador de Valdediós, San Vicente del Valle, y un largo etcétera), hasta épocas relativamente tardías no encontramos un claro precedente a los ejemplares románicos: la galería meridional de San Miguel de Escalada. Ésta, además, adelanta algunas de las características definitorias de los ejemplares construidos entre los siglos XI y XIII: uso cementerial, disposición y ubicación de la arcada y, sobre todo, su carácter abierto ${ }^{23}$. No en vano, podemos percibir notables similitudes entre el señalado caso de Escalada y ejemplos de gran antigüedad como la galería porticada de San Miguel, en San Esteban de Gormaz (fig.3).

22 Es especialmente frecuente la confusión terminológica entre "atrio" y "pórtico", hecho que ha generado expresiones tan imprecisas para referirse a nuestro objeto de estudio como "atrio porticado", únicamente aceptable, y no sin reservas, para casos tan peculiares como el de Santa María de Eunate, en Muruzábal (Navarra). No obstante, esta arquería perimetral encierra no pocos misterios, e incluso parece haber sido fruto de varias campañas constructivas entre las que mediaron bastantes décadas. MARTÍNEZ ÁLAVA, Carlos J., "Muruzábal", en GARCÍA GUINEA, Miguel Ángel y PÉREZ GONZÁLEZ José María (dirs.), MARTÍNEZ DE AGUIRRE, Javier (coord.), Enciclopedia del Románico en Navarra, II, Aguilar de Campoo, Fundación Santa María la Real. Centro de Estudios del Románico, 2008, p. 880.

23 Es preciso señalar que Martínez Tejera, en un trabajo bastante reciente, ha señalado la posibilidad de que esta galería porticada de Escalada no sea obra del hasta entonces aceptado siglo X, sino de mediados del siglo XI: MARTÍNEZ TEJERA, Artemio Manuel, El templo del monasterium de San Miguel de Escalada: "arquitectura de fusión" en el reino de León (siglos X-XI), Madrid, 2005, pp. 140-141. 


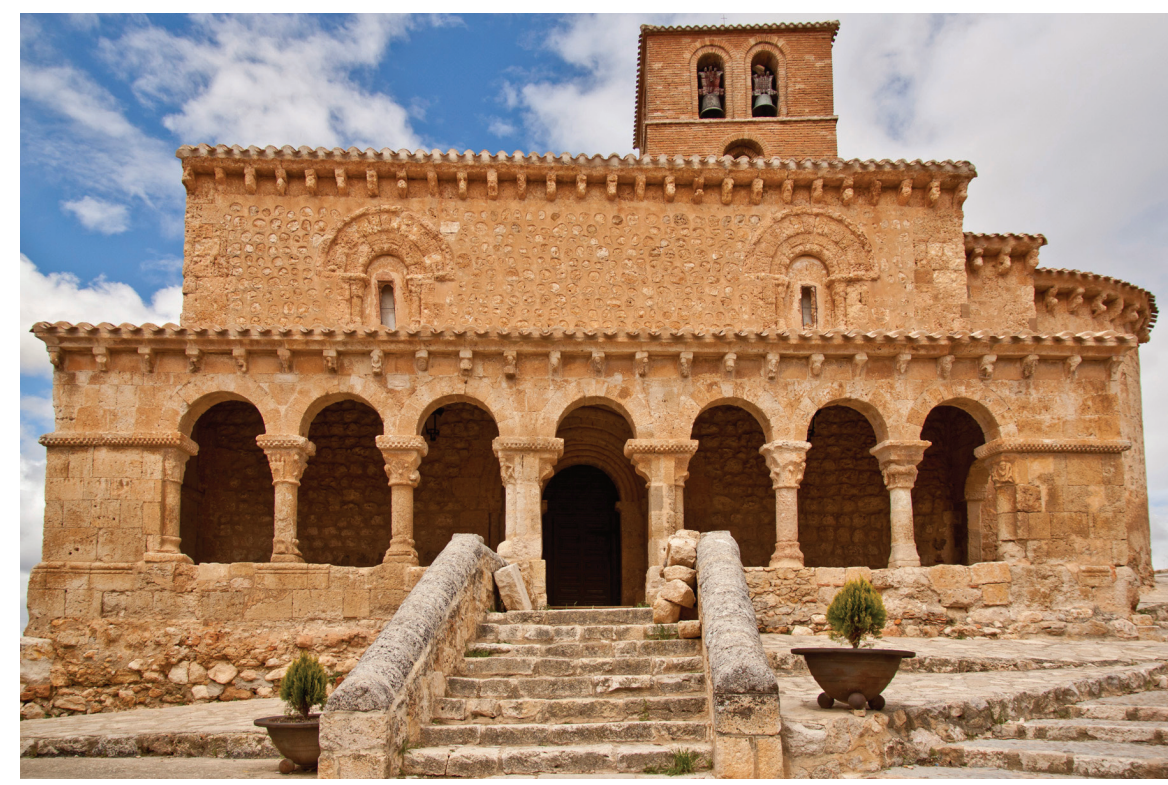

Fig. 3. Iglesia de San Miguel, San Esteban de Gormaz (Soria), último cuarto S. XI. [Foto autor].

La cronología del pórtico sanestebeño ha sido el epicentro de un importante debate, centrado en la lectura de la fecha que aparece en uno de sus canecillos. Según la interpretación establecida por Ortego y Frías, su descubridor, el epígrafe reza "+IVLIA/ NVS MA/GISTER/ FECIT/ ERA/ MC/ XV/ IIII"; sin embargo, la corriente iniciada por Álvarez Terán y González Tejerina considera más plausible "MC/ XLV/ IIII"24. De la aceptación de una u otra, por tanto, dependía la consideración de la obra como la más antigua del románico del entorno del Duero, precediendo incluso a la cercana iglesia de El Salvador de Sepúlveda, en cuyo ábside aparece la data de $1093^{25}$. Debido al interés que despertaba este asunto, el Proyecto Cultural Soria Románica efectuó un estudio exhaustivo de la pieza que confirmó la hipótesis inicial de Ortego y Frías, rechazando la existencia de una "X" virgulada ${ }^{26}$. No obstante, y aun aceptando la poco probable data de 1111, seguiríamos hablando del pórtico románico más antiguo

24 ALVAREZ TERÁN, Concepción y GONZALEZ TEJERINA, Mercedes, "Las iglesias románicas de San Esteban de Gormaz", en Boletín del Seminario de Estudios de Arte y Arqueología, n 3, 1934-1935, pp. 299-330.

25 CONTRERAS Y LÓPEZ DE AYALA, Juan, Marqués de Lozoya, "La epigrafía de las iglesias románicas de Segovia”, en Boletín de la Sociedad Española de Excursiones, n³9, 1931, p. 258

26 Pese a que la fecha que leyó Ortego y Frías en el canecillo del pórtico de San Miguel ha sido debatida durante décadas, las recientes investigaciones efectuadas por el "Proyecto Cultural Soria Románica" la han ratificado. LORENZO ARRIBAS, Josemi, "Canecillo (réplica)", en Paisaje interior (2009), op. cit., p. 577. Abordamos más extensamente este asunto en SALGADO PANTOJA, J. A., "Las galerías porticadas de San Esteban de Gormaz: legado artístico de una sociedad de frontera”, en Liño, no 18, 2012, pp. 19-29. 
de los conservados en el románico castellano, muy anterior al siguiente ejemplar datado (y no con pocas reservas), de la ermita de Tiermes (¿1182?) ${ }^{27}$.

El otro aspecto fundamental que hemos analizado con respecto a los pórticos románicos ha sido el concerniente a su morfología, su contenido y sus usos. En el terreno estrictamente físico, la mermada pero aún importante nómina de ejemplares conservados en Castilla, superior al centenar si se contabilizan los vestigios menores, nos permite extraer una serie de datos primordiales para su estudio. Atendiendo a las diferentes tipologías, podemos clasificar las galerías por su número de pandas. En referencia a ello, y aunque hoy prevalecen ejemplares de brazo único, existen indicios en un buen número de pórticos simples que permiten sospechar un origen acodado (Aldehuelas de Sepúlveda, San Bartolomé de Atienza, Beleña de Sorbe, Madrona, Pineda de la Sierra, El Salvador de Segovia), hecho que en casos como Alcozar ${ }^{28}$ o Andaluz $^{29}$ ha podido ser ratificado por la arqueología.

Por su parte, la ubicación de las galerías suele ser más reiterativa: se abren al sur del templo (al sur y oeste las de desarrollo acodado), aprovechando así el calor y la luz del sol. Menos habituales son las estructuras situadas al norte, hecho que viene motivado, como así indican los casos particulares, por condicionantes del terreno y por la propia ubicación del núcleo poblado: aparecen ejemplos en Alcozar, Baides, Castroserna de Abajo, Fuentidueña y Tortonda.

Otro aspecto diferencial en las galerías es la disposición de su arquería, que sólo en casos muy aislados repite la serie de siete vanos por frente, entendida por algunos autores como "modelo ideal" ${ }^{30}$. Las pruebas materiales, sin embargo, apuntan en dirección contraria, pues sólo algunos casos como San Miguel de San Esteban de Gormaz y otros pórticos relativamente cercanos como los de Rejas de San Esteban, Berzosa, Grado del Pico o Fuentemizarra ${ }^{31}$, poseen dicha configuración. Aunque sí existe una preferencia por el número impar de arcos, no necesariamente el siete, la realidad es que los pórticos solían adaptarse a las dimensiones de la nave, y su número de vanos, por tanto, dependía tanto de esa longitud como de los intereses o las pretensiones de los constructores. En consecuencia, existe toda una casuística que engloba desde los

27 CASA MARTÍNEZ, Carlos de la y RODRÍGUEZ ADRADOS, Jesús Víctor, "Cartelas medievales de Tiermes (Soria)", en El Románico en Silos. IX Centenario de la consagración de la iglesia y claustro. 10881988, Santo Domingo de Silos, Abadía de Silos, 1990, pp. 559-563.

28 YUSTA BONILLA, José Francisco, DIESTRO ORTEGA, Francisca, GONZALO CABRERIZO, César, et alii, "Estrategia de actuación ante una ruina románica. La ermita de la Virgen del Vallejo en Alcozar (Soria)", en VI Congreso Internacional Restaurar la Memoria: La gestión del Patrimonio hacia un planteamiento sostenible (Valladolid, 31 de octubre al 2 de noviembre de 2008), II, Valladolid, 2010, pp. 45-50.

29 YUSTA BONILLA, José Francisco, "La iglesia de San Miguel de Andaluz (Soria), de la singularidad al tipo" en III Simposi sobre Restauració Monumental (Barcelona, del 19 al 21 de noviembre de 1992), Barcelona, 1993, pp. 197-204.

30 Sobre este asunto se profundiza en ESTERAS MARTÍNEZ, José Ángel y LORENZO ARRIBAS, Josemi, "Siete arcos, siete infantes. Leyendas en torno al origen de las galerías porticadas románicas", Actas del I Congreso Internacional sobre "los siete infantes de Lara: la historia frente a la leyenda" (Salas de los Infantes, 13 al 15 de julio de 2011), en prensa. Agradecemos a los autores que nos hayan facilitado el acceso a este trabajo, aún inédito.

31 También hay casos aislados más alejados como los de Abánades, Frumales, Jaramillo de la Fuente, Nieva y Pinarejos. 
tres huecos existentes en Vizcaínos de la Sierra hasta los catorce que se abren en la panda sur de Carabias.

Con respecto a los materiales edificativos destaca el sillar escuadrado de caliza o arenisca, si bien existen casos realizados con mampostería o ladrillo ${ }^{32}$, e incluso podemos aventurar la existencia de un buen número de pórticos de madera hoy desaparecidos. La mayoría de las cubriciones poseen armadura lígnea bajo tejado a un agua, y no es infrecuente la existencia de bancos corridos de piedra en su interior, de gran utilidad para el uso social de la galería. La arquería suele descansar sobre capiteles decorados y fustes simples o pareados sobre basa de perfil ático y plinto. Las cornisas se exornan con molduras y canecillos, a los que se añaden, sobre todo en los casos más sobresalientes del románico segoviano, metopas, cobijas y arquillos (como ocurre en San Juan de los Caballeros de Segovia y Sotosalbos). Otro elemento reseñable son los accesos a los pórticos, en ocasiones ricamente decorados e individualizados, llegando a crearse verdaderas portadas monumentales como la occidental de Revilla de Orejana, la meridional de Canales de la Sierra o la mayoría de las creadas en las obras de los talleres que trabajan en el entorno de Duratón.

Otro aspecto importante en el plano arquitectónico fue la búsqueda de una correcta estabilidad y firmeza en las galerías, conjugando los aspectos compositivos y constructivos con una buena proporción y armonía formal. El gran escollo a resolver para lograr un equilibrio estructural óptimo fueron las cargas verticales que ejercía la techumbre sobre la propia galería. Una excesiva anchura del espacio transitable conllevaba mayores requerimientos estructurales; igualmente, un mayor tamaño, peso o inclinación de la cubierta hacían necesarias vigas de mayor grosor y robustez. También era primordial la buena construcción de la arquería, pues de ello dependía la mejor repartición de las cargas verticales, y el refuerzo extraordinario de los esquinales en los pórticos acodados, especialmente vulnerables a las fracturas ${ }^{33}$. Para ello a veces se construyen arbotantes interiores, como el existente en Saúca o el que hasta hace pocas décadas podía verse en Carabias.

La dimensión iconográfica, por su parte, plantea más dificultades, pues resulta complicado afirmar la existencia de representaciones peculiares o características en las estructuras porticadas. La mayoría de ellas, creaciones populares, reflejan la influencia de las principales obras de referencia en la zona. Así, en el entorno burgalés de la Sierra de la Demanda se reiteran, desde mediados del siglo XII hasta la centuria siguiente, algunos modelos vegetales y teriomórficos desplegados por el segundo maestro del claustro bajo de Silos y los talleres que trabajan en la galería superior: Jaramillo de la Fuente, Pineda de la Sierra, Vizcaínos de la Sierra, etc. Esta irradiación, amplificada hacia el sur por otras creaciones de tradición silense como la catedral de El Burgo de Osma, alcanza algunas obras de Soria (Arganza, Caracena, Tiermes) o

\footnotetext{
32 Así sucede en el recién descubierto pórtico de la iglesia de San Pedro de Paones. Más casos se conservan de ladrillo: Nieva y Pinarejos (con elementos sustentantes de piedra caliza), y Fuentepelayo, Orbita y Prádena del Rincón, obras efectuadas íntegramente con ladrillo.

33 Algunos de estos aspectos son analizados en la obra de ESTERAS MARTíNEZ, José Ángel, GONZALO CABRERIZO, César y LORENZO ARRIBAS, Josemi (2009), op. cit., pp. 127-129.
} 
Segovia (Bernuy de Porreros, Grado del Pico, Revilla de Orejana), aunque difuminándose paulatinamente según se aleja del núcleo de origen ${ }^{34}$.

Ya a principios del siglo XIII, la catedral de Sigüenza se convierte en otro importante foco artístico. Debido a ello, sus característicos capiteles foliáceos, palmeados o de hojas apuntadas, son copiados hasta la saciedad en buena parte de las iglesias porticadas de la diócesis: Jodra del Pinar, Saúca, Carabias, Laranueva, Tortonda, Cubillas del Pinar, etc. ${ }^{35}$ En idéntica centuria, ya en los albores del gótico, sobresale la producción de algunos talleres de tierras segovianas, siendo especialmente destacables para nuestros intereses los que desarrollan su labor en la propia ciudad de Segovia y en el área que se extiende entre ésta y el río Duratón. No en vano, en pequeñas localidades de esta área perduran pórticos tan sobresalientes como los de Sotosalbos, Revilla de Orejana, Perorrubio, San Pedro de Gaíllos o el de la propia iglesia parroquial de Duratón, considerada por Ruiz Montejo como cabecera de un importante taller escultórico. ${ }^{36}$

En consecuencia, y con la salvedad de algunos casos de gran entidad artística como algunas iglesias segovianas o la burgalesa de Rebolledo de la Torre, las representaciones que pueblan los capiteles, canecillos o molduras de las galerías porticadas no integran elaborados programas iconográficos. Al contrario, suelen ser escenas puntuales realizadas por escultores o talleres más o menos dotados, o incluso por simples canteros locales. No obstante, sí podemos señalar algunas que resultan bastante recurrentes, y que quizá puedan vincularse, no sin reservas, con las atribuciones funcionales o con el propio simbolismo del pórtico. Ese es el caso de las diferentes variantes de la psicomaquia, mostrada a través de luchas entre el hombre y la bestia irracional, o entre caballeros, a menudo ataviados y caracterizados con elementos claramente identificativos, quizá en un intento por representar la lucha entre el cristiano y el infiel. Sin embargo, aunque también los animales o seres imaginarios pueden aparecer en idéntica actitud beligerante, en la mayoría de las ocasiones se disponen afrontados, con un afán más decorativo que narrativo.

También es frecuente encontrar en los capiteles escenas bíblicas muy reconocibles. Entre ellas, destacan la Epifanía ante los Reyes Magos y la visita de las tres Marías al

34 Sobre la influencia del repertorio silense en otras obras castellanas, consideramos imprescindible el trabajo de BOTO VARELA, Gerardo, Ornamento sin delito. Los seres imaginarios del claustro de Silos y sus ecos en la escultura románica peninsular, Santo Domingo de Silos, Abadía de Silos, 2001. Para el caso concreto de la Sierra de la Demanda, también resulta muy recomendable el artículo de PALOMERO ARAGÓN, Félix, "El lenguaje románico en la Sierra de la Demanda", en GIL-DÍEZ USANDIZAGA, I. (coord.), Arte medieval en La Rioja: prerrománico y románico. VIII Jornadas de Arte y Patrimonio Regional (Logroño, 29 y 30 de noviembre de 2002), Logroño, 2004, pp. 109-210.

35 Profundizamos sobre este asunto en SALGADO PANTOJA, José Arturo, "Talleres de filiación seguntina en el románico del Alto Henares: el caso de las iglesias porticadas", en Actas del XII Encuentro de Historiadores del Valle del Henares (Alcalá de Henares, 25-28 de noviembre de 2010), Guadalajara, 2010, pp. $455-469$

36 "El templo de Duratón es aquí el inicio de la conformación de un taller que va a difundir por un área geográfica relativamente pequeña formas y pautas de trabajo elaboradas y concretizadas en esta iglesia [...] Duratón debe tomarse, pues, como comienzo de la cronología de taller. Podría situarse en el primer cuarto del siglo XIII al unísono del proceso constructivo global y coetáneo que va a dar lugar al románico rural segoviano". RUIZ MONTEJO, Inés, El románico de Villas y tierras de Segovia, Madrid, Encuentro, 1988, p. 250. 


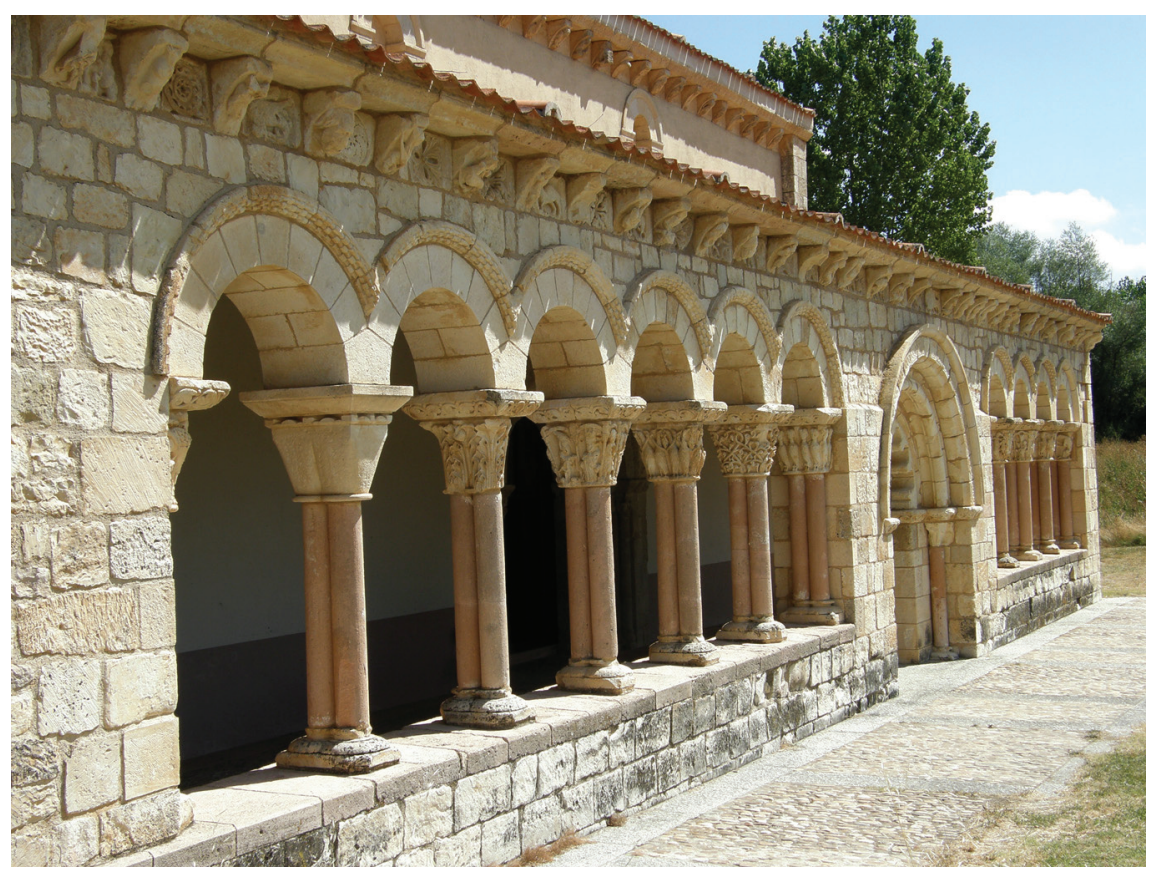

Fig. 4. Pórtico de la iglesia de La Asunción de Nuestra Señora, Duratón (Segovia), principios S. XIII. [Foto autor].

santo sepulcro, presentes en un buen número de pórticos segovianos y sorianos. Estos temas, aparte de marcar unos hitos fundamentales en la historia crística, pues son la manifestación de su presencia humana y su resurrección, fueron muy populares en el Medioevo en parte gracias a los tropos y dramas litúrgicos que se representaban, curiosamente, en el ámbito de la iglesia: el Quem quaeritis y el Ordo stellae. En menor medida, es posible hallar alusiones a la Maiestas Domini, al apostolado, la crucifixión de Cristo, etc. De igual manera, cabe mencionar la aparición de algunas estampas cotidianas, propias de la sociedad del momento (labores del campo, vida privada, ocio), y, sobre todo, un amplísimo repertorio vegetal, que recuerda, a modo de fronda pétrea e incorruptible, el simbolismo de eternidad que encierra un espacio litúrgico y funerario como el pórtico (fig.4).

La galería porticada también contó con una dimensión práctica para los lugareños, llegando a albergar eventos lúdicos, festivos, e incluso ligados al propio funcionamiento del municipio. Ejemplos documentados de ello son las reuniones para discernir los asuntos relativos al concejo o a la justicia local ${ }^{37}$, el desarrollo de algunas

37 “A partir del siglo XIII se aprovecharon estos sitios (pórticos) para reuniones laicas. Antes existió en las iglesias europeas la prohibición de celebrar audiencias laicas en estos espacios, y por lo que a España respecta tal prohibición existía ya en la legislación visigoda, y tal norma continuaba en 1322 según ordenaba en canon XVIII del Concilio de Valladolid. Esta normativa generalizada no siempre fue cumplida, y a partir del siglo 
actividades mercantiles ${ }^{38}$, o la celebración de festividades $\mathrm{u}$ otras actividades para el esparcimiento de los vecinos ${ }^{39}$. No obstante, las características antes citadas, unidas a las propias necesidades derivadas de la liturgia, también convirtieron al pórtico en un lugar idóneo para el desarrollo de ciertos acontecimientos vinculados con la vida del cristiano y que no tenían cabida, por unos u otros motivos, en el interior del templo: el catecumenado, los cumplimientos penitenciales o la estación mayor de las procesiones ${ }^{40}$.

Cabe también señalar el importante cometido protector del pórtico, pues aparte de tratarse de una estructura cubierta y resguardada, también se hallaba al amparo de un radio en torno al templo sacro, inviolable y bajo jurisdicción episcopal. Debido a ello, así como a diversas prohibiciones expresadas en algunos concilios medievales, parte de estas tierras patrimoniales extramuros fueron lugar de inhumación hasta fechas relativamente recientes. De ese modo, el atrio y sobre todo la galería porticada se convirtieron los lugares preferidos para este $\mathrm{fin}^{41}$, quedando generalmente destinados a las elites sociales o religiosas, ávidas de reposar eternamente en los espacios más próximos a la puerta del templo, acceso simbólico al paraíso ${ }^{42}$.

XIII hay documentación sobre las reuniones judiciales celebradas en los atrios y pórticos de las iglesias, lo que por otra parte era lógico, pues las ciudades y pueblos medievales no tenían otros espacios tan idóneos como éstos: en ellos se reunían municipios y se administraba la justicia”. SEBASTIÁN LÓPEZ, Santiago, Mensaje simbólico del arte medieval: arquitectura, liturgia e iconografia, Madrid, Encuentro, 1994. p. 300.

38 Por ejemplo, en una escritura de compraventa fechada en Segovia el 15 de septiembre de 1260 se dice: "esta carta fue hecha en el portegado de Sant Martin, miercoles XV dias del mes de setiembre en era de mille e CC e LXXXX e VIII annos". Cit. MORTERERO Y SIMÓN, Conrado, Apuntes de iniciación a la paleografía española de los siglos XII a XVII, Madrid, Hidalguía, 1979, p. 99.

39 A menudo podemos encontrar tableros de juego grabados en los basamentos de los pórticos. La mayoría de ellos responde al denominado alquerque o quirkat, cuyas reglas ya recoge por escrito Alfonso X en su Libro de los juegos: açedrex, dados e tablas. Del mismo modo, es presumible que estos espacios también albergasen en la Edad Media representaciones de carácter teatral o juglaresco, si bien disponemos de muy poca información al respecto. Sobre estos aspectos profundizamos más en SALGADO PANTOJA, José Arturo, "Las dimensiones simbólica y funcional de la galería porticada románica", en Codex Aquilarensis, n 26, 2010, pp. 24-51.

40 BANGO TORVISO, Isidro Gonzalo (1975), op. cit., pp. 184-185.

41 Si bien la arqueología ha puesto de manifiesto sobradas veces el uso cementerial de los pórticos, la documentación de archivo también ofrece menciones sobre este aspecto. Una de las más tempranas aparece en un libro de fábrica de la iglesia soriana de Paones: en una visita de 1530 se especifican las cantidades de dinero a pagar por recibir sepultura en el templo, señalando que "en el portal todos los q. se sepultasen a Cien maravedíes". Archivo Histórico Diocesano de Osma-Soria, Sección Parroquias, Paones, Libro de Fábrica I (1520-1647), ref. 347/18, 1530, s/p. La costumbre continuaba vigente en el siglo XIX, como así demuestran otras tantas referencias: "En el lugar de Jodra del Pinar á quince días del mes de Abril de mil ochocientos y quatro años murio una pobre, de edad como de unos diez y siete años, natural de Sacecorbo, no recibio Sacramento alguno p. no haber avisado. Se enterro en el Portico de la Iglesia en el quarto sin puerta ni mediana a la pared puerta cerrada cal y canto, la q. se enterró de caridad". Archivo Histórico Diocesano de Sigüenza, Jodra del Pinar, Caja 2, Libro de Difuntos II (1730-1852), 15 de abril de 1804, s/p.

42 BANGO TORVISO, Isidro Gonzalo (1992), op. cit., p. 97. 


\section{METODOLOGÍA PARA EL INVENTARIO}

En nuestro trabajo previo para catalogar todos los pórticos románicos peninsulares conseguimos reunir evidencias de más de un centenar de obras, si bien en torno a un tercio de ellas están reducidas a mínimos vestigios. Con motivo de las visitas que hemos efectuado a todas y cada una de ellas, aprovechamos para realizar todo tipo de anotaciones sobre sus detalles y características, adjuntando también croquis de los alzados y planos de cada galería, necesarios para actualizar el apartado planimétrico que acompaña al análisis.

El hecho de que la práctica totalidad de las obras se concentre en las provincias de Segovia, Soria, Guadalajara y Burgos, con casos puntuales en Ávila y La Rioja y otros más discutibles en Madrid, Palencia y Valladolid, nos ha permitido centrar el estudio en las tierras coincidentes con la Castilla del inicios del siglo XIII, momento en el que la construcción de galerías porticadas románicas llega a su cenit. En dicho contexto cronológico, el territorio dominado por los monarcas castellanos abarcaba algo más de la mitad norte peninsular, siendo los territorios entre el Tajo y el Guadiana su frontera aproximada al sur, y los reinos de Aragón y Navarra sus límites hacia levante. En cualquier caso, no se han omitido las alusiones a otros pórticos existentes en las regiones de Navarra, Aragón o Cataluña, así como a algunos ejemplares de datación dudosa; unos y otros son referidos en un apartado destinado al estudio de otros casos y vestigios menores.

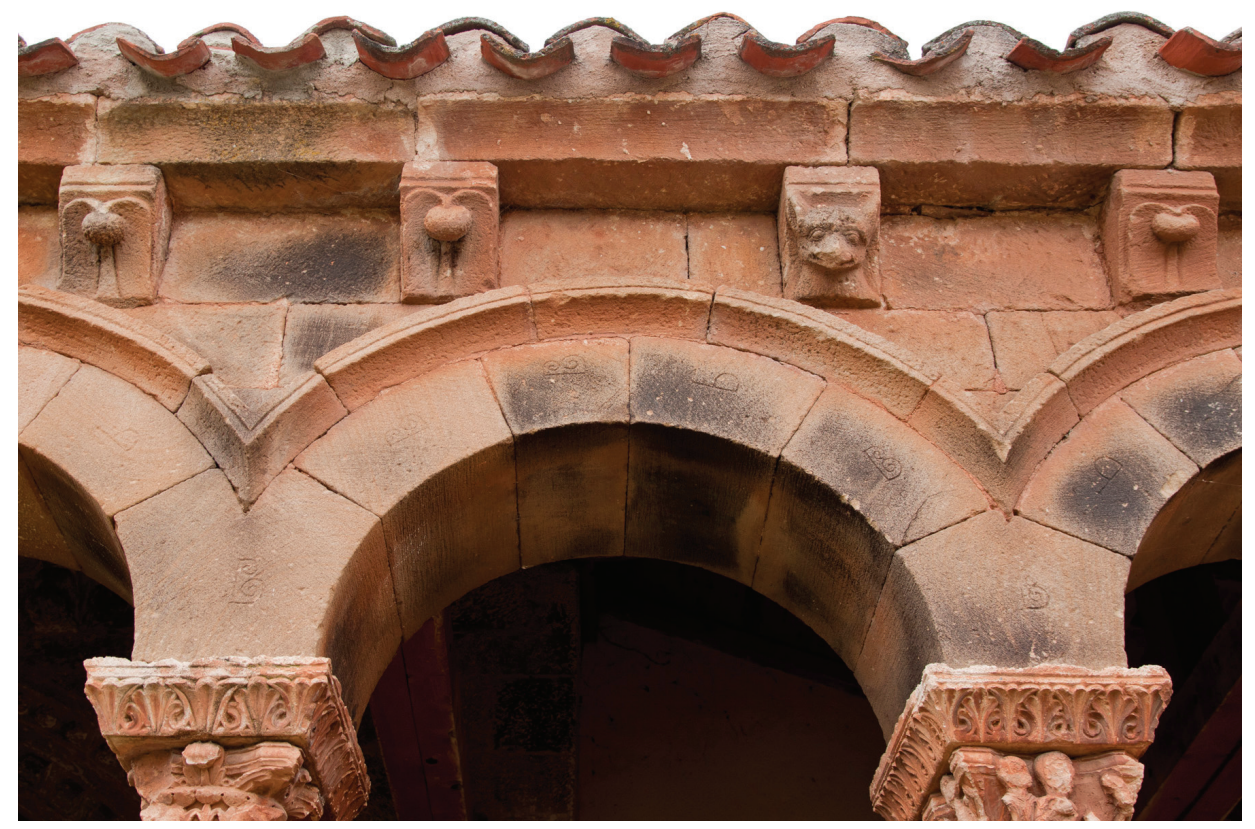

Fig. 5. Detalle del pórtico de la iglesia de La Asunción de Nuestra Señora, Jaramillo de la Fuente (Burgos), finales S. XII. [Foto autor]. 
Para hacer más accesible la investigación, se ha optado por realizar un inventario provincial y alfabético de obras. Cada una de ellas cuenta con un estudio pormenorizado, que comienza con una contextualización y descripción general del templo al que se adosan, atendiendo a su realidad material y a la posible evolución de su fábrica. Más tarde, se realiza un profundo análisis de todas las características de la galería porticada: detalles estructurales y formales, estudio de sus elementos escultóricos, localización de marcas lapidarias y otros elementos singulares, etc. En último lugar, y a tenor de la realidad material y de las filiaciones o relaciones con otras obras del entorno, se ofrece una cronología aproximada para la misma, identificando, si procede, los diferentes impulsos constructivos existentes en la obra. Del mismo modo, cabe señalar que existen dos apéndices finales en el trabajo, uno fotográfico y otro planimétrico, en los que se completa la información sobre cada uno de los ejemplares (fig.5).

Por último, y cuando resulta posible, hemos apoyado el análisis de las galerías porticadas con la documentación de archivo existente, material fundamental para conocer las transformaciones físicas y funcionales sufridas por los ejemplares en época postmedieval. En este sentido, nuestras principales fuentes han sido las existentes en los archivos histórico-diocesanos, en donde se conservan los libros de fábrica de las iglesias parroquiales y algunos informes de obra imprescindibles para hacer más precisa la investigación.

En cualquier caso, y aparte del catálogo ordenado de galerías porticadas, también se ha efectuado un amplio capítulo en el que se hace un nuevo análisis que trasciende los modernos límites provinciales. La finalidad del mismo es el establecimiento de grupos o líneas de filiación atendiendo a la realidad histórica del momento, a similitudes formales entre obras o incluso atendiendo a la labor itinerante de los talleres plenomedievales. El resultado es una visión mucho más rica y contextualizada, que constituye una de las principales aportaciones de nuestro trabajo al estudio del románico castellano. 